\title{
MADRUGADAS FIN DE SEMANA EN LA RADIO ESPAÑOLA ACTUAL: FICCIÓN, OCULTISMO Y HUMOR PARA EL RELATO RADIOFÓNICO
}

\author{
Virginia Guarinos \\ (Universidad de Sevilla) \\ guarinos@us.es
}

\begin{abstract}
Resumen: La programación del fin de semana, en general, es una de las zonas radiofónicas casi vírgenes en exploración investigadora y más aún lo es la franja horaria de madrugada. Esta colaboración quiere contribuir al análisis de esos programas, supuestamente poco oídos en las madrugadas de viernes, sábados y domingos. Lo hará de modo cuantitativo en relación al número de programas de la franja horaria referida en cadenas generalistas y a la cantidad de ficción en ellos representada; y de modo analítico buscando las claves del discurso narrativo radiofónico.
\end{abstract}

Palabras clave: Radio, narrativa, ficción, programación, géneros, formatos.

Abstract: The weekend programming is one of the most unexplored areas in radio research and further the late night and early morning. This contribution aims to complete the analysis of these programs, allegedly heard only a bit, of night-dawn Friday, Saturday and Sunday. It will do so in quantitative relation to the number of programs covering the slot in general-interest channels and the number of them represented in fiction and in terms of discourse analysis from the perspective of narrative radio.

Keywords: Radio, narrative, fiction, programming, genres, formats.

\section{ACOMPAÑADOS EN LA MADRUGADA}

- s la una en punto de la madrugada». Así comienza un programa desde - Unión Radio España, Ilamado Solos en la madrugada: "un espacio de reflexiones al alcance de todos los españoles". Con él se inicia la película Solos en la madrugada (J. L. Garci, 1978), una de las mejores representaciones de la radio noctámbula y el principio de su andadura en el panorama radiofónico español (Guarinos, 2002). Dispuesto a hacer una nueva radio, una radio-servicio, una radio-desahogo, el locutor protagonista de la película desarrolla este propósito con un tono de sermón laico radiofónico en busca de una catarsis personal y colectiva, reflejo de unos nuevos españoles pero también de una nueva forma de hacer radio de madrugada. Desde entonces hasta ahora, muchas cuestiones han evolucionado en esta franja horaria, aunque algunos no hayan reparado en ello. 
Madrugadas fin de semana en la radio española actual: ficción, ocultismo y humor para el relato radiofónico

En la web Portal Mundos aparece un "reportaje" firmado por Ruth García (2008) donde puede leerse lo siguiente referido a Hablar por hablar, a Encarna de noche y al consultorio sentimental de Elena Francis, "la más veterana" de la radio de madrugada (a quien sinceramente no recordamos como voz de la noche): "Muchos son los colectivos que se sienten unidos a este tipo de programas nocturnos. Los taxistas, los camioneros, los estudiantes, los solitarios e incluso algún que otro discapacitado mental son asiduos a los problemas de una parte de la población española que cada noche trasmite sus desgracias o deseos más ocultos en busca de un consejo". Remata el artículo la frase "programas nocturnos, unos espacios radiofónicos que son ya historia de la radio [...]". Partiendo de la idea evidente de que esto no es un reportaje, tal como figura en el portal, sino una columna de opinión (por otra parte, mal informada), lo leído denota una falta de simple observación objetiva del propio hecho de la radio de madrugada. Este tipo de programas a los que se refiere son los denominados programas de confidencias, uno de los variados tipos de programas y formatos que pueden oírse en la radio nocturna, un tipo de programa vinculado al talk show, tendencia moderna todavía por su correspondiente igual en la telerrealidad pero pionera en el panorama mediático español, donde la radio dio un paso adelante antes que la televisión. Un poco de memoria histórica nos lleva a situar cómo nacen estos programas que viven aún hoy y contextualizarlos en el conjunto de la programación de madrugada. Hay que situarse en la década de Solos en la madrugada para rescatar el devenir que ha ido experimentando esta franja de programación. La situación de la radio en ese momento pasa por la necesidad de vuelta a una radio-servicio, a una radio participativa, alentada por las radios libres y el cambio discursivo que se encamina a una nueva retórica cercana y natural que procure una comunicación menos engolada con el oyente.

Efectivamente, la frecuencia modulada, las radios libres, las radios piratas, trajeron un nuevo modo de hacer radio: por un lado, más informativa, por otro, más intimista, más cotidiana. En esta última vertiente entran en la programación los espacios nocturnos para insomnes. En 1980, dos años después del filme, se estrenaba en Radio Barcelona Solos en la madrugada de 1:00 a 4:00 de la madrugada, presentado por Joseph Cuní, creado en principio para resolver dudas o preguntas de oyentes y evolucionando a talk show, desapareciendo en 1984, justo en el momento en que otros programas del mismo corte comienzan a tomar las ondas (Balsebre, 1999). La madrugada es el terreno abonado para dejar hablar a los oyentes, para el servicio, para preguntas y respuestas, para fenómenos paranormales, para la radio-contacto que enlace a personas solitarias. Jesús Quintero aparecía en la SER con El loco de la colina; Carlos Herrera lo hace con Al borde de la cama a partir de 1987; José Manuel Parada en RNE con La noche de las sábanas blancas a finales de los 80; previo fue el Encarna de noche, de Encarna Sánchez (1978-1982, Radio Miramar). Todos estos programas tienen su continuidad en la actualidad y el exponente más duradero y exitoso es Hablar por hablar de la SER, en emisión todavía de lunes a viernes de 1:30 a 4:00 de la madrugada. 
En cualquier caso, no éste el único formato de radio para la noche. La madrugada ofrece en estos días un abanico de posibilidades que hacen del relato radiofónico una narración original, diferente y arriesgada. Se acepta comúnmente que la franja horaria de madrugada es la que comprende la horquilla de 00.00 a 06.00, a la que suceden las de mañana (de 06.00 a 13.00), mediodía (de 13.00 a 16.00), tarde (de 16.00 a 20.00) y noche (de 20.00 a 24.00). En ella caben otros programas que han llegado para cubrir la necesidad de una programación ininterrumpida 24 horas donde la participación del oyente se eleva a altas cotas, no sólo en programas de confidencias, también en otro tipo de espacios de preguntas-respuestas donde los propios oyentes inquieren informaciones variadas satisfechas por otros compañeros de ondas (Si amanece nos vamos, de la SER, La noche de los sabios, de Canal Sur Radio, por ejemplo). La actual radio generalista nocturna de madrugada arroja un tipo de programación diferente a la nocturna de diario, alcanzando una alta creatividad, conseguida en buena parte gracias al tiempo disponible para trabajar sobre productos grabados y editados que permiten una mayor complejidad narrativa y ficcional. Este trabajo previo no es desperdiciado si pensamos en que pudiera tener un escaso número de oyentes. Por un lado, hay que considerar que el oyente de noche es un oyente fiel: la radio de madrugada como radio servicio, como radio entretenimiento, o como radio compañía, cuenta con trabajadores, estudiantes o insomnes fidelizados a determinados programas. Por otro lado, los que duermen han encontrado una solución a la imposibilidad de audición en directo que ha desarrollado el podcasting ${ }^{1}$, puesto que son muchos los oyentes que recuperan los programas nocturnos fuera de su franja horaria natural, tantos que en muchos de estos programas se hace referencia y se saluda a esos oyentes que escucharán el programa al día siguiente o durante la semana. En definitiva, la radio de madrugada de fin de semana es una radio relajada, íntima pero también activa, participativa y creativa, tanto por parte del emisor como del receptor; es la radio de debajo de la almohada pero también la radio del ordenador para contactar con los chats y foros de los programas en directo 2 .

Pero no todo es tan optimista en lo que se refiere a las madrugadas, de diario o de fin de semana. Existe un problema en la propia programación radiofónica generalista que se extiende también al fin de semana y a la noche: la homogenización de la oferta programática. A nadie se le escapa que, con distintos presentadores-estrella y con distintas ideologías, la programación de

\footnotetext{
${ }^{1}$ Fenómeno que, gracias a las nuevas tecnologías digitales, está haciendo cambiar en brevísimo lapsus de tiempo el panorama radiofónico actual desde el punto de vista de la emisión, la programación e incluso de la creación, en tanto que ha supuesto la democratización de la comunicación sonora en diversos sentidos: cada vez son más los podcasts de audio de particulares, algunos muy elaborados y creativos, las emisoras por Internet llegan a lugares donde no alcanzaban las ondas, con el consiguiente desarrollo de la radio servicio en zonas rurales. Véanse al respecto las obras de Girard (2006), Cebrián (2008) o Tenorio (2008).

${ }^{2}$ Algunos de ellos casi ya forman parte de los colaboradores de los programas, aun usando la voz de los locutores para transcribir sus acciones participativas en los espacios, como sucede con los chatines de Hablar por hablar.
} 
Madrugadas fin de semana en la radio española actual: ficción, ocultismo y humor para el relato radiofónico

las cadenas españolas adolece, como también la televisión, de una falta, no de especialización, pero sí de marca personal. Las recientes publicaciones sobre ello apuntan a la misma dirección. Garcés (2007), quien sitúa el panorama radiofónico actual en una encrucijada alarmante de crisis económica, tecnológica, investigadora y profesional, igualmente extiende la alarma a la crisis intelectual, al afirmar que "el crecimiento del número de emisoras acontecido en las últimas décadas, lejos de significar un incremento en la diversidad de los discursos, ha representado en realidad la clonación indiscriminada de conceptos muy similares de programaciones". Este hecho resulta importante por dos motivos. El primero de ellos tiene relación con el nuevo panorama mediático de oferta online, para lo cual las radios deberían replantearse su concepto, teniendo en cuenta que no hay por qué ceñirse a ofrecer los podcasts de los programas emitidos por ondas, teniendo en cuenta que hay emisoras que empiezan a emitir sólo por Internet con una oferta especializada ${ }^{3}$. El segundo se refiere al sello personal de la emisora. Como afirma Murelaga (2007), la marca de estilo de una emisora está en la armonía y la coherencia de su programación. Si se tiene en cuenta este supuesto, la originalidad de las emisoras cae a niveles bajo mínimos. El problema para las emisoras, por tanto, no está en la programación sino en el tratamiento. Las emisoras, no dispuestas a renunciar a la competencia con otras al reproducir programas similares, deben encontrar sus estilemas en el tono general de cadena y de programas, y no sólo en las marcas ideológicas, en lo que sí procuran delimitar sus diferencias, sobre todo en la información.

La situación de parrilla de programas diferentes, marcados estilísticamente ${ }^{4}$, de autor, sugiere en muchos casos el miedo a la dishomogeneidad de los programadores que envían dichos programas a la nocturnidad de fin de semana $\mathrm{o}$ al sesteo de verano. Fuera de circuito han estado programas como La Ínsula Barataria $^{5}$, en las noches de Onda Cero, o La vuelta al mundo en ochenta libros ${ }^{6}$, en las tardes estivales de Radio 3, por poner algún ejemplo, que han llegado a la originalidad a través de la diferencia. También es de reconocer que éstos son los momentos para la distensión y para paladear buena radio, fuera de la tiranía del dominio de magazines e informativos.

\footnotetext{
${ }^{3} \mathrm{El}$ uso que se hace de Internet por parte de las cadenas tradicionales parece ceñirse a la posibilidad del consumo no lineal superando la temporalidad del medio radiofónico.

${ }^{4}$ Algunos bien podrían llamarse "de autor".

${ }^{5}$ Programa cultural de Onda Cero que alternaba reportajes con entrevistas dramatizadas a personajes históricos o ficcionales, como Napoleón o Colón. En este enlace de uno de sus creadores, el escritor Andrés Pérez Domínguez, junto con Cristóbal Cervantes ( http://laseparata.blogspot.com/2009/03/ entrevista-napoleonbonaparte.html) pueden oírse algunas emitidas en el verano de 2003. Véase "La Ínsula Barataria: un formato quijotesco para un programa de radio en la madrugada" (2003), en El libro andaluz, $\mathrm{n}^{\circ} 44$, pp. 25-27.

${ }^{6}$ Emitido bajo la responsabilidad de Macu de la Cruz durante el verano de 2008, consistente en veinticinco capítulos de cincuenta y cinco minutos cada uno, de lunes a viernes de 15.00 a 16.00 , donde se mezclaba realidad y ficción a propósito de ochenta obras maestras de la literatura universal.
} 


\section{LAS MADRUGADAS GENERALISTAS ESPAÑOLAS ACTUALES}

La oscuridad, la nocturnidad propicia la intimidad. Cuando terminan las tertulias políticas y las revistas deportivas, la noche se relaja. La programación de madrugada huye de la información, o mejor dicho, del formato informativo diario para adentrarse en otra manera de dar información de actualidad o no, una manera que tampoco se corresponde con el infotainment mañanero (al estilo Anda ya, Cuarenta Principales) o el infoshow humorístico (al estilo Los guiñoles, de Hoy por hoy, Cadena SER), sino que busca otros modos de acercarse o alejarse de lo actual para dar paso a otros formatos. Se toman como referencia tres de las cadenas generalistas más oídas en nuestro país, una pública y dos privadas: RNE, Cadena SER y Onda Cero.

\subsection{La madrugada laborable}

Una reflexión sobre la madrugada de fin de semana no puede hacerse en términos absolutos sin la relatividad que pueda aportar el conocimiento de la parrilla de madrugada del resto de la semana. Contemplando la programación de temporada ${ }^{7}$, los programas que pueden oírse son los siguientes.

Cuadro 1. Programación de madrugada de lunes a viernes.

\begin{tabular}{|c|c|c|c|}
\hline Horario & SER & RNE & ONDA CERO \\
\hline 00.00 & \multirow{3}{*}{$\begin{array}{l}\text { El larguero. José Ra- } \\
\text { món de la Morena. } \\
\text { Revista deportiva. }\end{array}$} & \multirow{2}{*}{$\begin{array}{l}24 \text { horas. Informa- } \\
\text { tivo. }\end{array}$} & \multirow{3}{*}{$\begin{array}{lr}\text { Al primer } & \text { toque. } \\
\text { Ángel } & \text { Rodrí- } \\
\text { guez. } & \text { Revista }\end{array}$} \\
\hline 00.30 & & & \\
\hline 01.00 & & \multirow{5}{*}{$\begin{array}{l}\text { Afectos en la noche. } \\
\text { Silvia Tarragona } \\
\text { (martes a jueves). } \\
\text { Magazine. }\end{array}$} & \\
\hline 01.30 & \multirow{4}{*}{$\begin{array}{l}\text { Hablar por hablar. } \\
\text { Macarena Berlín. } \\
\text { Programa de confi- } \\
\text { dencias. }\end{array}$} & & \multirow{4}{*}{$\begin{array}{l}\text { La parroquia de } \\
\text { El Monaguillo. } \\
\text { Sergio Fernán- } \\
\text { dez. Magazine } \\
\text { de humor. }\end{array}$} \\
\hline 02.00 & & & \\
\hline 02.30 & & & \\
\hline 03.00 & & & \\
\hline 04.00 & \multirow{5}{*}{$\begin{array}{l}\text { Si amanece nos va- } \\
\text { mos. Roberto Sán- } \\
\text { chez (de lunes a } \\
\text { jueves). Revista de } \\
\text { entretenimiento, pre- } \\
\text { guntas/respuestas. } \\
\text { Punto de fuga (de } \\
04.00 \text { a } 05.00 \text {, vier- } \\
\text { nes, Pablo Morán. } \\
\text { Revista otros lugares. } \\
\text { A buenas horas (de } \\
05.00 \text { a 06.00, vier- } \\
\text { nes, Puri Beltrán). } \\
\text { Entretenimiento mis- } \\
\text { celánea. }\end{array}$} & \multirow{5}{*}{$\begin{array}{l}\text { Afectos matinales. } \\
\text { Jordi Tuñón (mar- } \\
\text { tes a jueves). Ma- } \\
\text { gazine. }\end{array}$} & \multirow{5}{*}{$\begin{array}{l}\text { No son horas. } \\
\text { José Luis Salas } \\
\text { (lunes a jueves). } \\
\text { Magazine. } \\
\text { La fosforera. Ro- } \\
\text { cío Santos (vier- } \\
\text { nes). Recortes. }\end{array}$} \\
\hline 04.30 & & & \\
\hline 05.00 & & & \\
\hline 05.30 & & & \\
\hline 06.00 & & & \\
\hline
\end{tabular}

Fuente: Elaboración propia.

${ }^{7}$ Correspondiente a la temporada 2008/2009, en concreto a la programación de marzo de 2009. 
Madrugadas fin de semana en la radio española actual: ficción, ocultismo y humor para el relato radiofónico

Algunos de los más seguidos en la radio española se encuentran en este cuadrante. La parroquia de El Monaguillo, Hablar por hablar, Si amanece nos vamos, junto con los ya extinguidos El ombligo de la luna o La noche menos pensada (ambos de RNE), son de esos programas que arrasan en una hora en la que es difícil hacerlo. A simple vista, la homogeneidad de la programación nocturna deja de serlo en el momento en que terminan los programas deportivos. Son varias las consecuencias que se pueden extraer ante el conocimiento de las parrillas:

1. El desmarque de Radio Nacional. RNE se distancia de las otras cadenas privadas en el mantenimiento de un horario deportivo estandarizado. En su lugar, continúa con actualidad informativa hasta el horario de finalización de esos otros programas. Lo mismo sucede con el resto de la noche. Radio Nacional abarca la madrugada con sólo dos programas contenedores, magazines que alternan entrevistas, música, reportajes, tertulias con cambio de equipo y título a las 4.00 de la mañana. Su programación de "entre semana" no comienza en la madrugada del lunes como en las demás cadenas, sino que comienza en la del lunes al martes. Sus días de programación semanal discurren desde el lunes hasta el jueves. La programación especial de fin de semana afecta a las noches del viernes al sábado, del sábado al domingo y del domingo a lunes, una noche más de ocio radiofónico que el resto de emisoras.

2. La Cadena SER y Onda Cero mantiene coincidencias y homogeneidad entre sí, al menos en la programación y en los horarios en la madrugada. Ambas comienzan la programación nocturna de semana en la madrugada del viernes al sábado y recupera la semanal en la madrugada del domingo al lunes.

3. La marca de distanciamiento entre Onda Cero-RNE con respecto a la SER está en la primera banda horaria de madrugada. Las primeras apuestan por el magazine (el de Onda Cero, con marcado carácter humorístico), la segunda por el talk-show de confidencias, como sello corporativo, uno de sus buques insignia de madrugada.

4. El único punto en común de las tres noches se sitúa en la larga duración de los programas, con una media de dos programas para cubrir toda la madrugada ${ }^{8}$.

\subsection{La madrugada de fin de semana}

Parte de estas dishomogeneidades vistas durante la semana va a repetirse en las noches del fin de semana.

\footnotetext{
${ }^{8}$ Consideramos que hoy por hoy habría que replantearse la hora de inicio de la programación de madrugada desde el punto de vista teórico. El cambio de tono y la ruptura fuerte con lo anterior viene marcado por el paso de la información deportiva a los diversos formatos de magazines trasnochadores.
} 
Cuadro 2. Programación de madrugada de fin de semana.

\begin{tabular}{|c|c|c|c|c|}
\hline Cadena & Hora & Sábado & Domingo & Lunes \\
\hline \multirow{13}{*}{ RNE } & 00.00 & \multirow{4}{*}{$\begin{array}{l}\text { De película. Yolanda Flores. Re- } \\
\text { vista de cine. }\end{array}$} & \multirow{4}{*}{$\begin{array}{l}\text { Abierto hasta las dos. Palo- } \\
\text { ma Arranz. Música, humor y } \\
\text { cultura. }\end{array}$} & \multirow{4}{*}{$\begin{array}{l}\text { La transversal. Paco To- } \\
\text { más. Entretenimiento y } \\
\text { ficción. }\end{array}$} \\
\hline & 00.30 & & & \\
\hline & 01.00 & & & \\
\hline & 01.30 & & & \\
\hline & 02.00 & \multirow{4}{*}{\multicolumn{2}{|c|}{ Espacio en blanco. Miguel Blanco. Revista ocultismo. }} & Treinta y tanto Gabriela \\
\hline & 02.30 & & & Llanos. Magazine juvenil. \\
\hline & 03.00 & & & La estación azul. Ignacio \\
\hline & 03.30 & & & $\begin{array}{l}\text { Elguero. Revista de poe- } \\
\text { sía. }\end{array}$ \\
\hline & 04.00 & \multirow{2}{*}{$\begin{array}{l}\text { Con tres acordes. Manolo Fer- } \\
\text { nández. Musical. }\end{array}$} & \multirow{2}{*}{$\begin{array}{l}\text { Voces con swing. José Luis } \\
\text { Rubio. Musical. }\end{array}$} & \multirow{4}{*}{$\begin{array}{l}\text { Bienvenido a casa. Mavi } \\
\text { Aldana. Revista sobre } \\
\text { TVE y RNE. }\end{array}$} \\
\hline & 04.30 & & & \\
\hline & 05.00 & \multirow{2}{*}{$\begin{array}{l}\text { Frontera. Ángeles Fernández. } \\
\text { Religioso. }\end{array}$} & \multirow{2}{*}{ Fe y convivencia. Religioso. } & \\
\hline & 05.30 & & & \\
\hline & 06.00 & $\begin{array}{l}\text { Juntos paso a paso. Juan Fer- } \\
\text { nández Vegue. Minorías. }\end{array}$ & $\begin{array}{l}\text { Futuro abierto. Tato Puerto. } \\
\text { Actualidad en profundidad. }\end{array}$ & \multirow{2}{*}{$\begin{array}{l}\text { En días como hoy. Juan } \\
\text { Ramón Lucas. Informativo } \\
\text { matinal. }\end{array}$} \\
\hline & 07.00 & Nómadas. Álvaro Soto. Viajes. & $\begin{array}{l}\text { RNE en primera persona. San- } \\
\text { dra Camps. Docudramático. }\end{array}$ & \\
\hline \multirow{12}{*}{ SER } & 00.00 & \multirow{3}{*}{$\begin{array}{l}\text { El larguero. José Ramón de la } \\
\text { Morena }\end{array}$} & \multirow{2}{*}{\multicolumn{2}{|c|}{ El larguero. Revista deportiva }} \\
\hline & 00.30 & & & \\
\hline & 01.00 & & \multirow{6}{*}{$\begin{array}{l}\text { Milenio 3. Iker Jiménez. Re- } \\
\text { vista información esotérica. }\end{array}$} & \multirow{3}{*}{$\begin{array}{l}\text { Los toros. Manuel Molés. } \\
\text { Revista taurina }\end{array}$} \\
\hline & 01.30 & \multirow{5}{*}{$\begin{array}{l}\text { Hablar por hablar. Macarena } \\
\text { Berlín. Confidencias. }\end{array}$} & & \\
\hline & 02.00 & & & \\
\hline & 02.30 & & & Punto de fuga. \\
\hline & 03.00 & & & \\
\hline & 03.30 & & & \\
\hline & 04.00 & \multirow[t]{2}{*}{ Punto de fuga. } & \multirow{4}{*}{$\begin{array}{l}\text { El cine. Carlos López Tapia. } \\
\text { Revista especializada. }\end{array}$} & \multirow[t]{4}{*}{ Si amanece nos vamos. } \\
\hline & 04.30 & & & \\
\hline & 05.00 & \multirow[t]{2}{*}{ A buenas horas } & & \\
\hline & 05.30 & & & \\
\hline \multirow{12}{*}{$\begin{array}{l}\text { ONDA } \\
\text { CERO }\end{array}$} & 00.00 & \multirow{2}{*}{$\begin{array}{l}\text { Al primer toque. Ángel Rodrí- } \\
\text { guez. Revista deportiva. }\end{array}$} & \multirow{2}{*}{$\begin{array}{l}\text { Radioestadio. } \\
\text { Contenido deportivo. }\end{array}$} & \multirow[t]{2}{*}{ Al primer toque } \\
\hline & 00.30 & & & \\
\hline & 01.00 & \multirow{6}{*}{$\begin{array}{l}\text { La parroquia de El Monaguillo. } \\
\text { Sergio Fernández. Magazine } \\
\text { humorístico. }\end{array}$} & \multirow{6}{*}{\multicolumn{2}{|c|}{$\begin{array}{l}\text { La rosa de los vientos. Bruno Cardeñosa. Revista miscelá- } \\
\text { nea curiosidades. }\end{array}$}} \\
\hline & 01.30 & & & \\
\hline & 02.00 & & & \\
\hline & 02.30 & & & \\
\hline & 03.00 & & & \\
\hline & 03.30 & & & \\
\hline & 04.00 & La fosforera. Rocío Santos. Re- & Partiendo de cero. Paco & No son horas. José Luis \\
\hline & 04.30 & cortes. & León. Revista divulgación & Salas. \\
\hline & 05.00 & & científica. & Magazine. \\
\hline & 05.30 & & & \\
\hline
\end{tabular}

Fuente: Elaboración propia. 
Madrugadas fin de semana en la radio española actual: ficción, ocultismo y humor para el relato radiofónico

Cuantitativamente, RNE cuenta con quince programas, Onda Cero con cuatro exclusivos de fin de semana y la SER con cinco programas. Comienzan las dos privadas la programación de fin de semana a las 4.00 de la mañana del viernes al sábado; RNE lo hace desde las 00.00. Y la suspenden a las 4.00 del domingo al lunes las privadas, mientras que Radio Nacional la prolonga hasta las 6.00 . Son seis horas más de programación exclusiva de fin de semana. La atomización de programas de menor duración en Radio Nacional apunta a una mayor oferta como parte de sus funciones de servicio público, al tratarse de una cadena pública.

Desde el punto de vista de los géneros y los contenidos, el número de programas incluye en la variedad de existencia de los mismos. La que mayor pobreza presenta es Onda Cero, que trabaja sobre la base de la tradición y el prestigio entre los oyentes de la revista La rosa de los vientos. Y llega incluso a utilizar un programa de reciclado de materiales propios, La fosforera. La SER ofrece mayor variedad entre sus géneros: revistas especializadas y magazines: ocultismo, cine, toros, viajes, cultura, etc. Radio Nacional apuesta también por la revista especializada y por la cultura, el humor, la ficción, sin olvidar lo religioso, la música o las minorías, ofreciendo una gama variada que cubra un espectro amplio de oyentes.

\section{CREATIVIDAD, RELATOS Y FORMATOS EN LA NOCHE}

De la tipología de participación de oyentes ${ }^{9}$ en función de la finalidad (Herrera, 2003) de su contacto, en fin de semana se reduce a la expresión de la opinión o aportación de información casi siempre de forma indirecta, a través de los chats o correos electrónicos, cuestión fácilmente justificable por el descenso de audiencia en el fin de semana en general. El oyente pierde un poco de protagonismo en el fin de semana como co-actor de la radio, colaborador en la "radiocracia" que durante la semana inunda las noches con las confesiones, el realce de una experiencia o el consultorio, actuaciones de los oyentes que han recuperado su auge desde la última década del siglo $\mathrm{XX}$, tendencia que está comenzando a generar numerosos podcasts de sonido a modo de relatos autodiegéticos fuera de las ondas en blogs y páginas web especializadas. El papel del conductor del programa también cambia; de la modalidad participativa en directo donde el locutor es amigo y confidente, el conductor y sus colaboradores recuperan un papel de sujetos de la enunciación y del enunciado y en muchos casos de personajes.

Aun tratándose de formatos conocidos como revistas especializadas o magazines, el género dominante en la madrugada del fin de semana es el entretenimiento con incursiones lingüísticas novedosas y creativas que suponen nuevos modos de representación de la ficción. Las madrugadas de los días de ocio son los momentos que algunos espacios eligen para intentar alejarse de la homogeneización. Dicha estandarización de la semana por competencia por la audiencia se basa, como afirman Gutiérrez y Huertas (2003), en:

\footnotetext{
${ }^{9}$ Expresar una opinión, rectificar una información, aportar información, relatar un caso propio o ajeno, consultar una información, denunciar un hecho o situación, desahogarse, pedir información u opinión $y$ concursar.
} 
el dominio claro de tres géneros en el conjunto de las cadenas (Información, Información/ Entretenimiento y Deporte) y las numerosas coincidencias en su ubicación en las parrillas (en más del $40 \%$ de la programación semanal todas las emisoras convergen en la oferta del mismo género), y obedecen al predominio de una política programática basada en la competencia directa. Los mayores contrastes se detectan durante el fin de semana, pero siempre y cuando dejemos a un lado el Deporte.

Esta homogeneidad también se da en el terreno del formato, pues el magazine parece ser que es el modelo que mejor resuelve la organización de los contenidos de la radio actual. Lo mismo sucede con los temas. Por ejemplo, en el género informativo, donde más variedad podría darse, la actualidad prevalece en todas las ofertas.

Radio Nacional se distancia en esta oferta de fin de semana ${ }^{10}$ en busca de la originalidad, no sólo en la oferta de programas, a veces con espacios altamente arriesgados y alternativos. Lo cierto es que en muchos casos la creatividad de otras cadenas puede no ser de formato o de programa o género, sino estar en el interior de los programas, en el tratamiento y su aporte a la reinvención de los géneros, más aún entendiéndose estos en función de contenidos, como propone Alcudia (2008). A medias programas de entretenimiento, a medias programas especializados, los siguientes programas mezclan cultura, curiosidades, música, dramatizaciones, relatos ficcionales, tertulias, entrevistas (algunas reales y otras no). De todos los programas posibles, se han seleccionado dos por sus altos índices de audición, vinculados a la fantasía, al esoterismo y al relato ficcionalizado (La rosa de los vientos y Milenio 3); el tercero, por su horario de emisión, cuenta con una audiencia a posteriori, que descarga el programa, pero que cuenta con una originalidad extrema en lo que a nuevos modos de ficcionalización se refiere (La Transversal).

\subsection{La rosa de los vientos}

Este programa goza de una larga tradición en la radio española. Ha pasado por varios momentos en su trayectoria desde 1997, cuando se llamaba Turno de noche; el más duro ha sido el de la pérdida de su creador, Juan Antonio Cebrián en 2008, junto con el año de desaparición de la parrilla, 2003. Con una media de 250.000 oyentes reales en directo (muchos más de descargas posteriores a la emisión: es junto a Milenio 3 el más descargado de nuestra radio), es el programa que se extiende hacia otros cauces de difusión, en tanto que son múltiples los libros de Cebrián ${ }^{11}$ realizados y vendidos al hilo de secciones del programa. Su propia página $w e b^{12}$, la personal del conductor citado y la del programa,

\footnotetext{
${ }^{10} Y a$ durante la semana Radio Nacional practica géneros no hegemónicos y se distingue en "Cultura y Música, y en ser la que más información especializada expone de forma individual: sólo RNE 1 dispone de espacios dedicados enteramente a la Historia, el Medio Ambiente y la Política en sus emisiones en cadena" (Gutiérrez y Herrera, 2003).

${ }^{11} \mathrm{El}$ último de ellos precisamente no es de Cebrián, sino sobre él, es el libro de Rueda y Casasola (2008).

${ }^{12}$ Página propia del programa y espacio en la página de la cadena respectivamente: http://rosavientos. es/ y http://www.ondacero.es/OndaCero/programa/La-rosa-de-los-vientos/2166771.
} 
Madrugadas fin de semana en la radio española actual: ficción, ocultismo y humor para el relato radiofónico

son vehículos para el contacto entre oyentes y otros interesados por los temas tratados en él. La rosa de los vientos es uno de los tres principales programas sobre fenómenos extraños y curiosidades de las noches del fin de semana ${ }^{13}$, junto a Milenio y a Espacio en blanco. La historia, la ciencia, la ecología, los servicios secretos y la parapsicología y el ocultismo son sus temas preferentes. Todos ellos se desarrollan hoy bajo la conducción de Bruno Cardeñosa en las secciones "La zona cero", "Azul y verde", "Pasajes de la Historia", "Terror y relatos", "Materia reservada" o "Callejón del escribano".

Tomando como referencia el programa del día 22 de marzo de 2009 se reparte, como viene siendo habitual, de este modo:

Cuadro 3. Segmentación de un programa de La rosa de los vientos.

\begin{tabular}{|c|l|l|l|}
\hline Hora & Secciones & Géneros & Temas \\
\hline $1^{\mathrm{a}}$ & Zona cero & Tertulia & 6 temas \\
\hline \multirow{2}{*}{$2^{\mathrm{a}}$} & Zona cero & $\begin{array}{l}\text { Tertulia y } \\
\text { consultorio }\end{array}$ & $\begin{array}{l}5 \text { temas (conexión con } \\
\text { corresponsal en EEUU) } \\
\text { Mails de oyentes }\end{array}$ \\
\hline \multirow{3}{*}{$3^{\mathrm{a}}$} & Termómetro & $\begin{array}{l}\text { Reportaje } \\
\text { Viajes }\end{array}$ & $\begin{array}{l}\text { Monografía agua } \\
\text { México }\end{array}$ \\
& La biblioteca & Entrevista & $\begin{array}{l}\text { Novedades esotéricas } \\
\text { Guerra del Golfo }\end{array}$ \\
& La cara B & Reportaje & \multicolumn{2}{|l}{} \\
\hline
\end{tabular}

Fuente: Elaboración propia.

Este programa es realizado en directo pero contiene segmentos grabados, algunas secciones al completo, como es el caso de "Termómetro de la Tierra" en éste en particular. Como se observa, se mantiene la misma tertulia durante casi dos horas, finalizada con quince minutos en la segunda hora de consultas de los oyentes sobre los temas tratados. La variedad y abundancia de temas es acorde con la gran extensión de la tertulia, formada por colaboradores fijos y eventuales del programa (cuatro en concreto) y en algunos casos con la conexión en directo con un corresponsal en el extranjero. Los temas rondan entre la curiosidad científica y lo inexplicable. Suele ser la tercera hora la que alberga una mayor variedad, no de temas, sí de secciones con nombre propio y temas monográficos que a veces adoptan la forma de entrevista (telefónicas, como la de viajes, o en estudio, como la de libros), hasta cuatro en total, equilibrando el

\footnotetext{
${ }^{13}$ No son excepciones, sino todo lo contrario. Cualquier cadena autonómica o local que se precie tiene un programa de este corte; hasta Radio Betis, cadena deportiva del mismo Club, cuenta con Voces del misterio (http://vocesdelmisterio.blogia.com/archivos/), o la cadena local Radiópolis Sevilla, que posee el espacio Las voces del miedo, por poner un par de ejemplos no nacionales.
} 
reparto temporal entre las mismas, que se encuentran separadas por transiciones musicales de canciones rock o pop.

El programa, en general, ofrece un desarrollo de información y opinión "normal". El trabajo de mayor imaginación recae en los relatos de Cebrián dentro de la sección "Pasajes de la Historia", quien a modo de narrador heterodiegético y focalizador omnisciente relata una historia de un personaje conocido de la historia. En dichos relatos se emplean la palabra, el silencio, la música y los efectos con valores expresivos y ambientales. La música, sobre todo, suele tener un valor gramatical, pero también expresivo y cronotópico, como los efectos lo posee ambiental para amueblar una escena donde rara vez se entra de modo directo, sin incursión de personajes en discurso directo, es decir, de forma dramatizada. El formato de estas narraciones es el de relato radiofónico de una pieza, con cabecera propia de sección de programa.

En general, el programa no recurre al efectismo de los tópicos del terror y los contenidos e intervenciones de los colaboradores son más descreídas y distanciadas que en otros programas hermanos.

\subsection{Milenio 3}

Este otro programa no puede decir lo mismo en cuanto a su tratamiento de los contenidos. Periodismo de lo desconocido, como gusta llamarlo a Iker Jiménez, su conductor, Milenio se desarrolla de igual modo a través de otros vehículos de comunicación ${ }^{14}$. En sus diferentes secciones caben tertulias, reportajes, intervenciones de oyentes, monografías y dramatizaciones. El corazón del programa es la sección "Expediente", donde se sigue un caso y, supuestamente, se rebate. "El informativo", a modo de batería de noticias, suele dar cuenta de novedades de arqueología, misterios, sucesos extraños... El clima de ficcionalización nada tiene que ver con la realidad no verosímil. También La rosa trata temas de realidad no verosímil y, no obstante, no cuenta con el tratamiento deliberadamente oscuro de los mismos. Las dramatizaciones son guionizadas por Iker Jiménez, con la voz de Carlos Barroso, y suelen hacerse sobre la recreación de casos sucedidos realmente. Estos relatos, totalmente ficcionales, son más elaborados que los del programa anterior. Cuentan con narradores homo o heterodiegéticos y personajes en un paso estructural del discurso indirecto de los narradores, en focalización omnisciente o subjetiva según el caso, al directo dramatizado interpretado sólo por los personajes de ficción.

Sin embargo, el clima de ficcionalización recorre buena parte de las introducciones del conductor principal y también de los reportajes de los colaboradores donde el tipo de entonación, de modulación de la voz, hacen que se conviertan no en voces informativas referenciales sino en voces actuativas dramáticas insertadas en entrevistas o reportajes con una clara intención de hacer un camino fácil, si no

\footnotetext{
${ }^{14}$ Con diversas páginas para su seguimiento: http://www.cadenaser.com/milenio3/, http://www.cadenaser. com/milenio3/ o la personal de Iker Jiménez, http://www.ikerimenez.com/contenidos.htm
} 
Madrugadas fin de semana en la radio española actual: ficción, ocultismo y humor para el relato radiofónico

al miedo del oyente, sí al menos de inquietud. La música sobre todo es usada, dentro de los clásicos tópicos del terror, como silencio relativo para reflexionar, además de su función gramatical y expresiva. El programa desarrolla tres tipos de relatos: el de ficción, el semificcional, donde alguno de los redactores hace una introducción actuativa o donde Iker Jiménez presenta noticias en la sección de informativo, y, por último, el relato de modelo de mundo de realidad efectiva, creando una ambientación narrativa de difícil diferenciación entre el mundo ficcional verosímil, el ficcional no verosímil y el modelo de mundo de realidad efectiva. Eso sí, los efectos sólo son usados en las dramatizaciones.

\subsection{La transversal}

Imposible de clasificar, RNE lo define como programa de entretenimiento. Independientemente de la dificultad de incursión del programa en cualquier tipología, es, sin duda, el más creativo de la madrugada de fin de semana, a pesar de que se trate, como ellos bien dicen, del único programa de fin de semana emitido los lunes ${ }^{15}$. Sketches, microrrelatos y microdramatizaciones, entrevistas creativas, serialidad, episodios, secciones varias hacen del programa un gran collage caracterizado por el uso explícito y voluntario de la ficción y de la fragmentariedad. El trabajo de producción y edición del programa queda patente en cada una de sus secciones, todas ellas muy elaboradas y en la cantidad de las mismas. Por comparación, obsérvese en este cuadro, cómo se construye la primera hora del programa, del mismo día de emisión que el referido en La rosa de los vientos:

\section{Cuadro 4. Secciones de la primera hora de programa de La transversal.}

\begin{tabular}{|c|c|c|c|}
\hline Hora & Secciones & Género & Temas \\
\hline 0.00 & Inicial & $\begin{array}{l}\text { Entrevista en } \\
\text { profundidad }\end{array}$ & Varios \\
\hline 0.10 & Editorial & Opinión & Actualidad \\
\hline 0.13 & Reportaje & Múltiple cultural & $\begin{array}{ll}\text { - } & \text { Cómic } \\
\text { - } & \text { Libro } \\
\text { - } & \text { Olimpiadas matemáticas }\end{array}$ \\
\hline 0.20 & Tontuberías & Microrrelato & Ficción fantástica \\
\hline 0.22 & $\begin{array}{l}\text { Aventuras de Enrique } \\
\text { y Ana }\end{array}$ & Serial & $\begin{array}{ll} & \text { Actualidad política } \\
\text { - } & \text { Actualidad deportiva }\end{array}$ \\
\hline 0.33 & La tesis de Kalen & Serial & $\begin{array}{l}\text { - Ironización sobre medios } \\
\text { comunicación }\end{array}$ \\
\hline 0.38 & Tontuberias & Microrrelato & Ficción fantástica \\
\hline 0.41 & Canción & & \\
\hline 0.45 & Boletín informativo & & \\
\hline
\end{tabular}

Fuente: Elaboración propia.

${ }^{15}$ Dirección oficial donde poder enlazar a sus podcasts: www.rtve.es/programas/latransversal. 
En cuarenta y cinco minutos, son siete las secciones que se producen y una canción de cierre para enlazar con el boletín horario. Es evidente la agilidad que proporciona la brevedad de cada una de las secciones. Algunas de ellas son usadas como segmentos gramaticales de paso de unas secciones a otras. Como es el caso de las "Tontuberías", montajes de cortes de bandas sonoras de películas que enlazadas entre sí derivan en un nuevo significado. La existencia de ficción está presente desde el primer momento, desde la entrevista creativa que suele dar inicio al programa sin aviso previo. Es una entrevista en profundidad a un personaje de la cultura o el espectáculo donde Paco Tomás, el director, ejerce el papel de ingenuo amistoso que termina derivando la entrevista hacia el diálogo donde el entrevistado puede introducir temas nuevos, e incluso ser el entrevistador el que termine contestando preguntas. Esta zona no ficcional, al menos no claramente ficcional, se completa con los reportajes impresionistas donde el narrador puede construirlo en primera persona dando paso a dos o tres noticias con intercalado de voces testimoniales o entrevistas de expertos sobre los temas tratados, arropados por música de fondo y sin presentaciones previas de los entrevistados, que se presentan a sí mismos.

La mayor carga ficcional está en los dos seriales, Las aventuras de Enrique y Ana, y La tesis de Kalen. Ambas mantienen estructuras seriadas con tramas episódicas puntuales y personajes fijos principales y secundarios eventuales al estilo del tradicional serial radiofónico. La forma es la de la dramatización, en tanto que no existe narrador salvo en el prólogo que acompaña cada capítulo (26, segunda temporada, del primero, en el programa referido). Ambos cuentan con sus propias sintonías de cabecera y su desarrollo completo de categorías de esferas de acción, de personajes, además de las propiamente de estructuras narrativas, llegando a ser complejas (en la inclusión de flash-backs y puestas en abismo) y metalingüísticas (pues en más de una ocasión los personajes reflexionan sobre la estructura del capítulo o sobre sus propias condiciones de personajes de ficción poco coherentes). El humor es el objetivo, ya no el terror o el miedo, de la elevación de estos mundos ficcionales. Lo paródico en la construcción de personajes y en los temas de actualidad ridiculizados en las tramas pone de manifiesto el público al que va dirigido, el oyente deseado. Las abundantes referencias a la cultura de los años 80 del siglo XX, el propio estilo fragmentario, irónico del programa en lo referente a las éticas políticas y empresariales, más el estilo "petardo" de los personajes, denotan un target de audiencia entre la treintena y la cuarentena.

Ese ritmo ágil complica la decodificación por la densidad de los contenidos y estímulos sensoriales en el uso de todos los elementos sonoros y no sonoros de la radio en sucesión y en simultaneidad. Estamos ante un entretenimiento activo, en el sentido de que exige atención, escucha, y no sólo audición, por parte del oyente, quien debe estar atento en tanto que la conducción del programa es mínima y las secciones se suceden sin presentación alguna por yuxtaposición. 
Madrugadas fin de semana en la radio española actual: ficción, ocultismo y humor para el relato radiofónico

\section{A MODO DE CONCLUSIÓN}

Desde el punto de vista cuantitativo, la atomización es la característica más evidente de la radio de madrugada de fin de semana, con una abundancia de programas y variedad de los mismos en cuanto a contenidos, siendo la revista especializada el género más encontrado. Dentro de ellos se diferencia la presencia de minorías de destinatarios oyentes en las cadenas públicas con respecto a las privadas, que se decantan de un modo más homogéneo por terrenos curiosos u ocultos de temas de escasa trascendencia como corresponde a la zona de la semana en la que se encuentran. La tradición del imaginario colectivo occidental vincula el humor, la fantasía y la ciencia ficción con el divertimento, con el tiempo de ocio, y así procede ya de la literatura, el teatro o el cine, o más recientemente videojuegos, juegos de rol y otras prácticas dependientes de la industria del entretenimiento.

Discursivamente, de entre todos los programas citados, unos son más originales que otros, más trabajados y tratados técnicamente. Los últimos son los que presentan unas estructuras fragmentarias e hibridación de géneros, características ambas muy modernas, en las que cabe la creatividad y la ficción como base dominante junto con el gusto por la microforma, el microrrelato o la microdramatización. Así son ciertas secciones de Milenio 3, La rosa de los vientos - La transversal. Estos programas emitidos en directo cuentan con muchos materiales grabados y montados, que les permiten generar dicha complejidad narrativa, aunque la mayor parte de programas de este estilo pierden la frescura que aporta la participación directa del oyente, aunque ganen en arquitectura de relato radiofónico sofisticado.

\section{REFERENCIAS BIBLIOGRÁFICAS}

ALCUDIA, M. (coord.) (2008): Nuevas perspectivas sobre los géneros radiofónicos. Madrid: Fragua.

BALSEBRE, A. (coord.) (1999): En el aire. 75 años de radio en España. Madrid: Cadena Ser.

CEBRIÁN, M. (2008): La radio en Internet. Buenos Aires: La Crujía.

GARCÉS, R.: "La crisis de los discursos radiofónicos", Revista Latina de Comunicación Social, $n^{\circ} 62$ (2007). Disponible en http://www.ull.es/publicaciones/latina/200719RaulGarces. htm [Consulta: 12 marzo 2009].

GARCÍA, R. (2008): "Los programas de radio nocturnos", Portal Mundos. Disponible en (http://www.portalmundos.com/mundoradio/generos/nocturnos.htm) [Consulta: 23 marzo 2008].

GIRARD, B. (2006): Secreto a voces: radio, nuevas tecnologías de información y comunicación e interactividad. FAO. Disponible en http://comunica.org/secreto/html/ descargar.htm. [Consulta: 25 marzo 2008]. 
GUARINOS, V.: El cine y la radio. En UTRERA, R. (ed.) (2002): Cine, arte y artilugios. Sevilla: Padilla Libros, pp. 91-128. Disponible en http://www.cervantesvirtual.com/servlet/ SirveObras/12036180817819384098213/p0000002.htm\#l 6_ [Consulta: 20 marzo 2009].

GUTIÉRREZ, M.; y HUERTAS, A.: "La programación de las radios generalistas en España", Zer, $\mathrm{n}^{\circ} 15$ (2003). Disponible en http://www.ehu.es/zer/zer15/articulo 7.htm [Consulta: 12 marzo 2009].

HERRERA, S.: "Tipología de la participación de los oyentes en los programas de radio", Anàlisi, no 30 (2003), pp.145-166.

MURELEAGA, J.: "Reflexiones sobre la transformación del concepto de programación radiofónica. De la parrilla al mensaje", Palabra clave, 10, n 2 (2007) http://sabanet. unisabana.edu.co/comunicacion/palabraclave/archivo017.htm [27 marzo 2009].

RUEDA, F.; y CASASOLA, S. (2008): Fuerza y honor: Juan Antonio Cebrián y los pasajes de su historia. Madrid: Temas de Hoy.

TENORIO, I. (2008): La nueva radio. Manual completo del nuevo radiofonista. Barcelona: Marcombo.

\section{Breve semblanza biográfica de la autora}

Virginia Guarinos es Profesora Titular de la Universidad de Sevilla. Doctora en Comunicación Audiovisual y en Ciencias del Espectáculo. Directora del equipo de investigación ADMIRA, en análisis de medios, imágenes y relatos audiovisuales. Trabaja en Narrativa fílmica, televisiva y radiofónica, estudios culturales y de género.

(Recibido el 11-05-2009, aceptado el 08-03-2010) 